\title{
DESENVOLVIMENTO DE UM MODELO MATEMÁTICO PARA DETERMINAÇÃO DO REQUERIMENTO DE ENERGIA DE MOAGEM DA RESERVA DE MINÉRIO DE FERRO DA SAMARCO MINERAÇÃO S.A.*
}

\section{Resumo}

Rafael de Souza Rodrigues ${ }^{1}$ Leonardo Esteves Bonfioli ${ }^{1}$ Paulo Sérgio Mapa² Leônidas Angelo Pinto ${ }^{3}$

A Samarco Mineração está entre os grandes produtores mundiais de pelotas de minérios de ferro com início de suas operações em 1977 na lavra e beneficiamento de minérios itabiríticos friáveis de médio a baixo teor de Ferro. No Quadrilátero Ferrífero a formação ferrífera bandada, devido a sua gênese, apresenta, no geral, um menor teor de Fe e uma maior compacidade com o aumento da profundidade. Com a crescente demanda mundial de minério de ferro, existe a necessidade da incorporação dos materiais de menor teor e maior dureza visando o aumento das reservas. O aproveitamento desses minérios impacta significativamente as etapas de beneficiamento, sendo o processo de moagem o mais afetado, suscitando a necessidade de desenvolver ferramentas para prever 0 comportamento do minério nessa etapa do processamento mineral. A partir do modelo geológico-tipológico pré-existente e da introdução dos testes de determinação do tempo de moagem (DTM) e do requerimento energético da moagem nas amostras de furos de sonda, desenvolveu-se um modelo matemático para o cálculo do requerimento energético do minério na moagem. Como resultado deste trabalho, a variável "energia" (kWh/t) foi inserida no modelo de blocos da reserva podendo ser utilizada pelo planejamento de lavra de curto prazo para adequação do minério à energia de moagem existente e pelo planejamento de longo prazo para antever a necessidade de revamp nas usinas existentes e/ou para auxiliar no dimensionamento de novas instalações de moagem.

Palavras-chave:Minério de Ferro; Moagem; Requerimento energético.

\section{DEVELOPMENT OF A MATHEMATICAL MODEL FOR DETERMINING THE GRINDING ENERGY OF SAMARCO IRON ORE RESERVE}

\begin{abstract}
Samarco, which is among the major iron ore pellets producers of the world, started its operations in 1977 with the exploitation and processing of soft iron ore of medium to low iron grade. Inside Quadrilátero Ferrífero, the banded iron formation, due to its genesis, presents a lower Fe grade and greater compactness with depth increase. With the increase of iron ore global demand, it became necessary to introduce lower grade ores with higher hardness to increase reserves. The exploitation of these ores significantly impacts the beneficiation processes, mainly the grinding stage, leading to a necessity of developing tools to predict the behavior of the ore in this stage of mineral processing. From the pre-existing geologicaltypological model and from the introduction of the determination of grinding time (DTM) and the grinding energy requirement test at the technological characterization of the drill core samples, it was developed a mathematical model for calculating the grinding energy requirement of the ore types. As a result of this study, the variable "energy " (kWh/t) was inserted in the block model and it can be used for the short-term mine planning in adapting the ore to the existing grinding energy and for the long-term mine planning to anticipate the necessity of revamp in the existing plants and to assist in the design of new facilities grinding mills.

Keywords: Iron ore; Itabirite; Grid energy; Griding.

\footnotetext{
1 Geólogo, Gerência de Planejamento de Mina, Samarco Mineração S.A., Mariana, MG, Brasil.

2 Especialista em Processo, Gerência de Engenharia de Processo, Samarco Mineração S.A., Mariana, MG, Brasil.

3 Técnico de Processo, Gerência de Engenharia de Processo, Samarco Mineração S.A., Mariana, MG, Brasil.
}

\footnotetext{
* Contribuição técnica ao $44^{\circ}$ Seminário de Redução de Minério de Ferro e Matérias-primas, 15 Simpósio Brasileiro de Minério de Ferro e 2o Simpósio Brasileiro de Aglomeração de Minério de Ferro, 15 a 18 de setembro de 2014, Belo Horizonte, MG, Brasil. 


\section{INTRODUÇÃO}

A Samarco Mineração S.A. está entre os grandes produtores mundiais de pelotas de minérios de ferro. Desde o início de suas operações em 1977 na mina do Germano, foi pioneira e tornou-se benchmark na lavra e beneficiamento de minérios itabiríticos friáves de médio a baixo teor de Ferro.

A formação ferrífera bandada está presente em todo o Quadrilátero Ferrífero sendo considerada como uma camada guia, dando forma e contorno a uma das mais importantes províncias metalogenéticas do mundo. São rochas constituintes da formação Cauê, pertencentes à sequência de rochas metassedimentares paleoproterozóicas do supergrupo Minas [1]. No contexto do Complexo Alegria (porção leste do QF), processos tectono-metamórficos sobre os sedimentos ferríferos originais, com superposição de processos supergênicos, foram os eventos fundamentais na gênese do minério de ferro [2]. O processo supergênico está associado aos processos intempéricos por águas meteóricas que levam à dissolução e lixiviação do quartzo, acarretando na concentração relativa dos óxidos de ferro. Como consequência desses processos ocorre o abrandamento da rocha sã com a formação dos corpos itabiríticos friáveis [3]. Em maiores profundidades, onde o processo supergênico é normalmente menos atuante, existe a tendência dos corpos de minério de ferro apresentarem menores teores de $\mathrm{Fe}$ e maior compacidade.

No caso da Samarco, a incorporação dos minérios de baixo teor de Fe e de maior dureza, além da flexibilização dos cut off's em PPC (perda por calcinação ou perda ao fogo) e fósforo, possibilitou o aumento da reserva para a ordem de 3 bilhões de toneladas, sustentando consecutivas expansões da empresa.

Contudo, o aproveitamento dos minérios de maior compacidade impacta significativamente nas diversas etapas do processo produtivo da Samarco sendo o processo de moagem o mais afetado. Minérios mais duros/consistentes demandam maior requerimento energético, acarretando em grande dificuldade para atender as especificações com as taxas nominais de alimentação, no caso da Samarco, 10\% retido na malha de $150 \mu \mathrm{m}$. Com isso, a obtenção da liberação mineral, necessária ao processo de flotação é comprometida, prejudicando a obtenção das especificações de qualidade do concentrado e de índices otimizados de recuperação metálica.

O modelo geológico-tipológico da Samarco é fundamentado pela composição mineralógica dos itabiritos para diferenciação e definição dos tipos, pois oferecem características intrínsecas, químicas e físicas, a cada um deles, e remetem a natureza e intensidade dos processos geológicos atuantes na gênese do minério $[4,5]$. Para classificação do minério quanto à compacidade é utilizado o retido mássico acumulado na malha de $3 / 8 "(9,53 \mathrm{~mm})$. Os materiais são classificados como compacto quando o retido em $3 / 8$ " é maior do que $80 \%$, são semi compactos quando o retido em 3/8" é maior do que $60 \%$ e menor do que $80 \%$ e será classificado como friável quando o retido mássico é menor do que $60 \%$ na malha de $3 / 8 "$.

Indubitavelmente, o modelo geológico-tipológico atualmente concebido na Samarco é o alicerce para um modelo geometalúrgico, constituindo um instrumento de previsibilidade desde o planejamento de lavra até o controle integrado de qualidade dos concentrados e pelotas produzidas. Contudo, dentre outras lacunas, percebeuse que o conceito de compacidade baseado apenas na estratificação granulométrica apresentava baixa aderência com o comportamento dos diversos minérios no processo de moagem.

\footnotetext{
* Contribuição técnica ao $44^{\circ}$ Seminário de Redução de Minério de Ferro e Matérias-primas, 15오 Simpósio Brasileiro de Minério de Ferro e 2ํ Simpósio Brasileiro de Aglomeração de Minério de Ferro, 15 a 18 de setembro de 2014, Belo Horizonte, MG, Brasil. 
Desta forma, fez-se necessário o desenvolvimento de ferramentas que possibilitem a previsão do comportamento do minério para a etapa de moagem.

O ensaio de requerimento energético, realizado rotineiramente na Samarco para os compostos mensais das amostras de alimentação das usinas, fornece o consumo específico de energia para os moinhos industriais. $O$ método desenvolvido por Donda [6] considera a equação de Rowland para a previsão do consumo de energia em moinhos de pequeno diâmetro.

Os resultados obtidos nos ensaios de laboratório apresentam boa correlação com os dados industriais, conforme demonstrado por Donda, Galinari e Rabelo [7].

O ensaio de requerimento energético é a ferramenta que traz a relação direta do comportamento do minério ao conceito de eficiência de moagem, fornecendo subsídios para o controle operacional do circuito de moagem e para o dimensionamento de novas instalações. Sendo assim, o objetivo desse trabalho foi inserir nos modelos de blocos de longo e curto prazo o requerimento energético $(\mathrm{kWh} / \mathrm{t})$, possibilitando ao planejamento de lavra de curto prazo a adequação do minério à energia de moagem existente e ao planejamento de longo fornecer à Engenharia de Processos recursos para antever a necessidade de revamp nas usinas existentes e/ou auxiliar no dimensionamento de novas instalações de moagem.

\section{METODOLOGIA}

O principal suporte amostral para atualização dos modelos geológicos e de blocos é obtido por sondagem rotativa diamantada com broca no diâmetro de $7,78 \mathrm{~cm}$. São realizados furos de $50 \mathrm{~m}$ de profundidade (pré-lavra) na malha $50 \times 50 \mathrm{~m}$, e furos de $400 \mathrm{~m}$ (profundo vertical) ou $600 \mathrm{~m}$ de profundidade (profundo exploratório) na malha de $100 \times 100 \mathrm{~m}$ ou $100 \times 150 \mathrm{~m}$, dependendo da mina (figura 1). Ao longo dos últimos 5 anos a Samarco realizou mais de $150.000 \mathrm{~m}$ de sondagem em suas minas.

Os testemunhos de sondagem são encaminhados para a descrição geológica, onde serão definidas as amostras segundo a composição mineralógica, qualidade química e características físicas dos itabiritos. O padrão adotado na descrição é que cada amostra deverá possuir em média $8 \mathrm{~m}$, com tolerância de $\pm 4 \mathrm{~m}$, respeitando a altura do banco de lavra de $24 \mathrm{~m}$. Os testemunhos são cortados transversalmente, metade permanece na caixa arquivada em um galpão de testemunhos, e a outra metade da amostra é encaminhada para caracterização em escala de bancada.

Todas as amostras de testemunhos de sonda são encaminhadas para caracterização em escala de bancada. No fluxograma completo de caracterização (figura 1) são realizados ensaios de britagem, moagem, deslamagem e flotação, análise granulométrica do ROM (séries grossa, média e fina da sequencia de peneiras da série Tyler), análises químicas do ROM, alimentação da flotação (ROM deslamado) e concentrado final, análises mineralógicas da alimentação da flotação e concentrado e análise do grau de liberação do quartzo do retido na malha de $150 \mu \mathrm{m}$.

\footnotetext{
* Contribuição técnica ao 44 Seminário de Redução de Minério de Ferro e Matérias-primas,

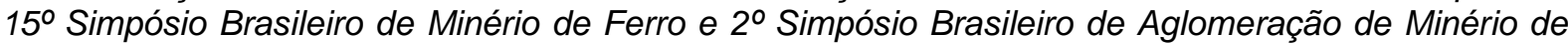
Ferro, 15 a 18 de setembro de 2014, Belo Horizonte, MG, Brasil. 


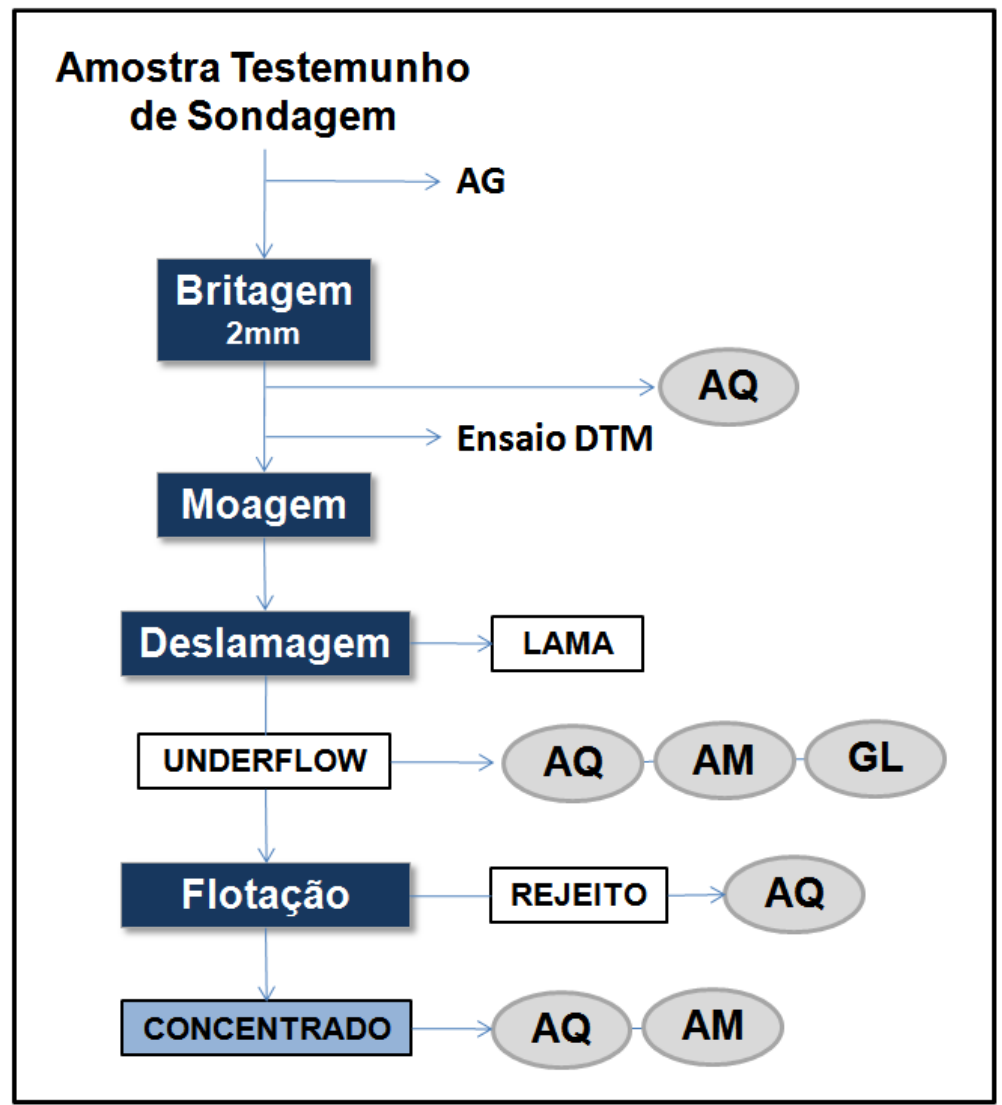

Figura 1. Fluxograma esquemático da caracterização das amostras de testemunhos de furos de sondagem. AG - Análise Granulométrica; AQ - Análise Química; AM - Análise Mineralógica; GL Grau de liberação $(+150 \mu \mathrm{m})$.

No fluxograma de caracterização é realizado o ensaio de DTM (determinação do tempo de moagem) considerando a especificação de $10 \%$ retido na malha de $150 \mu \mathrm{m}$. O procedimento do teste é relativamente simples, realizado em um moinho $8 \times 12$ " com rotação ajustada em $67 \mathrm{rpm}$. A amostra é quarteada de forma a obter três alíquotas, uma das alíquotas será moída em 600 segundos, a segunda alíquota deverá ser moída em um tempo maior ou menor, dependendo do resultado do primeiro teste. É realizada análise do retido mássico em $150 \mu \mathrm{m}$ na alíquota da amostra sem estar moída (tempo zero) e para as duas alíquotas moídas nos respectivos tempos. Os resultados são apresentados em um gráfico, onde no eixo das ordenadas estão as percentagens retidas na malha de controle e no eixo das abcissas estão plotados os tempos da moagem. Pela curva gerada é possível calcular qual o tempo necessário para obter $10 \%$ retido em $150 \mu \mathrm{m}$ no ensaio de moageme assim alcançar a liberação mineral necessária para o processo de flotação.

$\mathrm{Na}$ figura 2, é possível observar a distribuição espacial dos furos de sonda que contém resultados de DTM, nas minas de Alegria Norte e Alegria Sul da Samarco.

\footnotetext{
* Contribuição técnica ao 44ํㅗㄴ Seminário de Redução de Minério de Ferro e Matérias-primas, 15오 Simpósio Brasileiro de Minério de Ferro e 2ํ Simpósio Brasileiro de Aglomeração de Minério de Ferro, 15 a 18 de setembro de 2014, Belo Horizonte, MG, Brasil. 

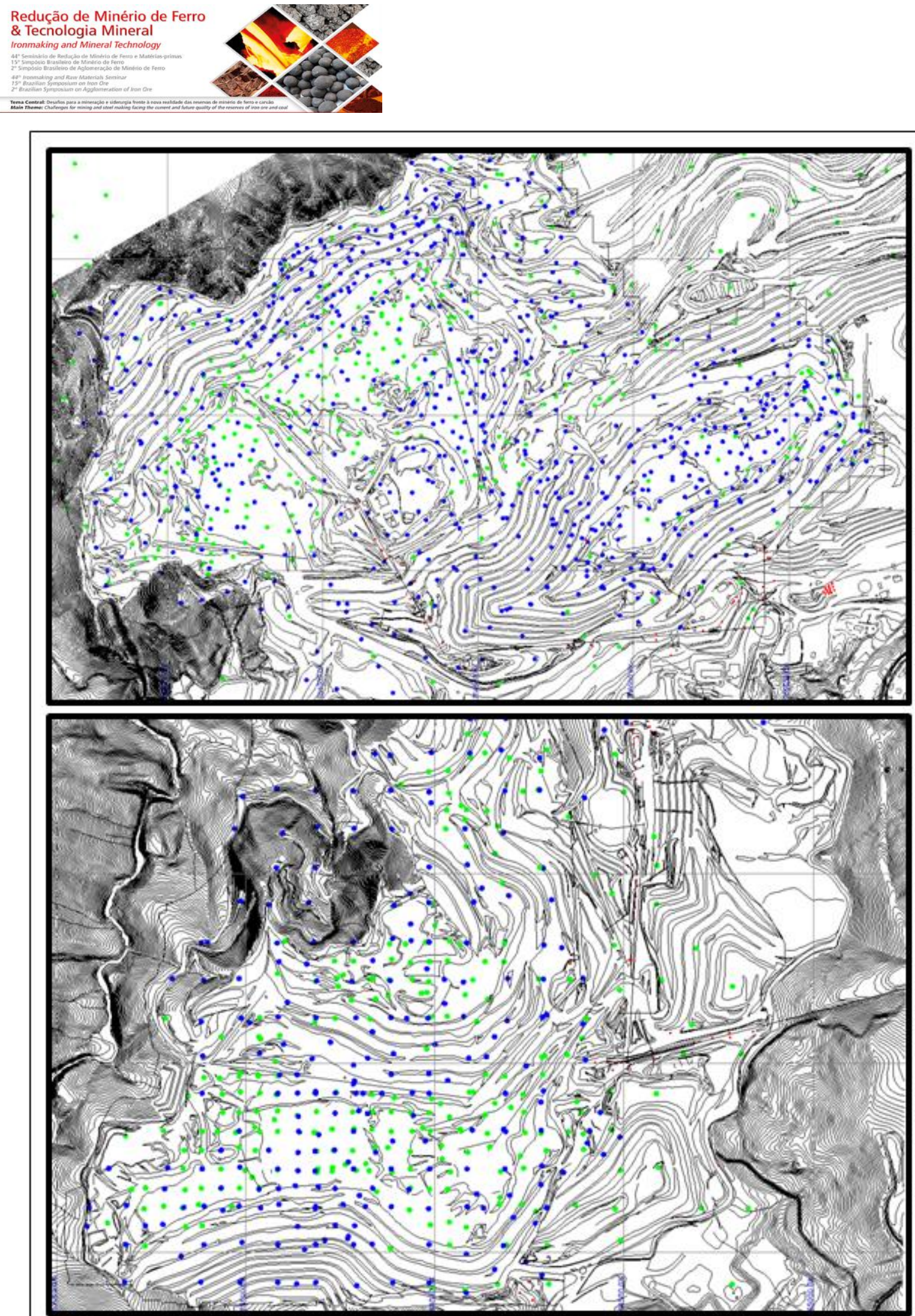

Furos de sonda com resultados de análises granulométrica, química, mineralógica, e caracterização nos ensaios de bancada.

Furos de sonda com resultados de DTM e análises granulométrica, química, mineralógica, caracterização nos ensaios de bancada

Figura 02. Mapa topográfico das minas de Alegria Norte e Alegria Sul da Samarco, atualmente em operação de lavra, com a distribuição dos furos de sonda executados.

Em 2013, foi inserido no fluxograma de caracterização das amostras de furos de sonda o teste de requerimento energético da moagem. No ensaio de requerimento

* Contribuição técnica ao 44 Seminário de Redução de Minério de Ferro e Matérias-primas, 15ํ Simpósio Brasileiro de Minério de Ferro e $2^{\circ}$ Simpósio Brasileiro de Aglomeração de Minério de Ferro, 15 a 18 de setembro de 2014, Belo Horizonte, MG, Brasil. 


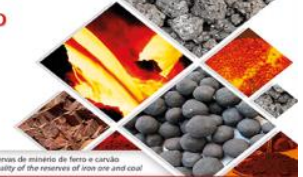

energético é utilizado um moinho de 12×12" com rotação ajustada para 53,5 RPM e escalonamento da carga moedora bem definida e controlada. A amostra é quarteada de forma a obter 5 alíquotas. Uma delas será referente ao tempo zero e as outras quatro alíquotas deverão ser moídas em tempos distintos. Em todas as alíquotas deverá ser analisada o retido mássico em $150 \mu \mathrm{m}$. Como resultado obtêm-se a energia necessária para a moagem do minério até $10 \%$ retido em $150 \mu \mathrm{m}$, obtido na equação da curva exponencial ajustada, conforme gráfico da figura 3.

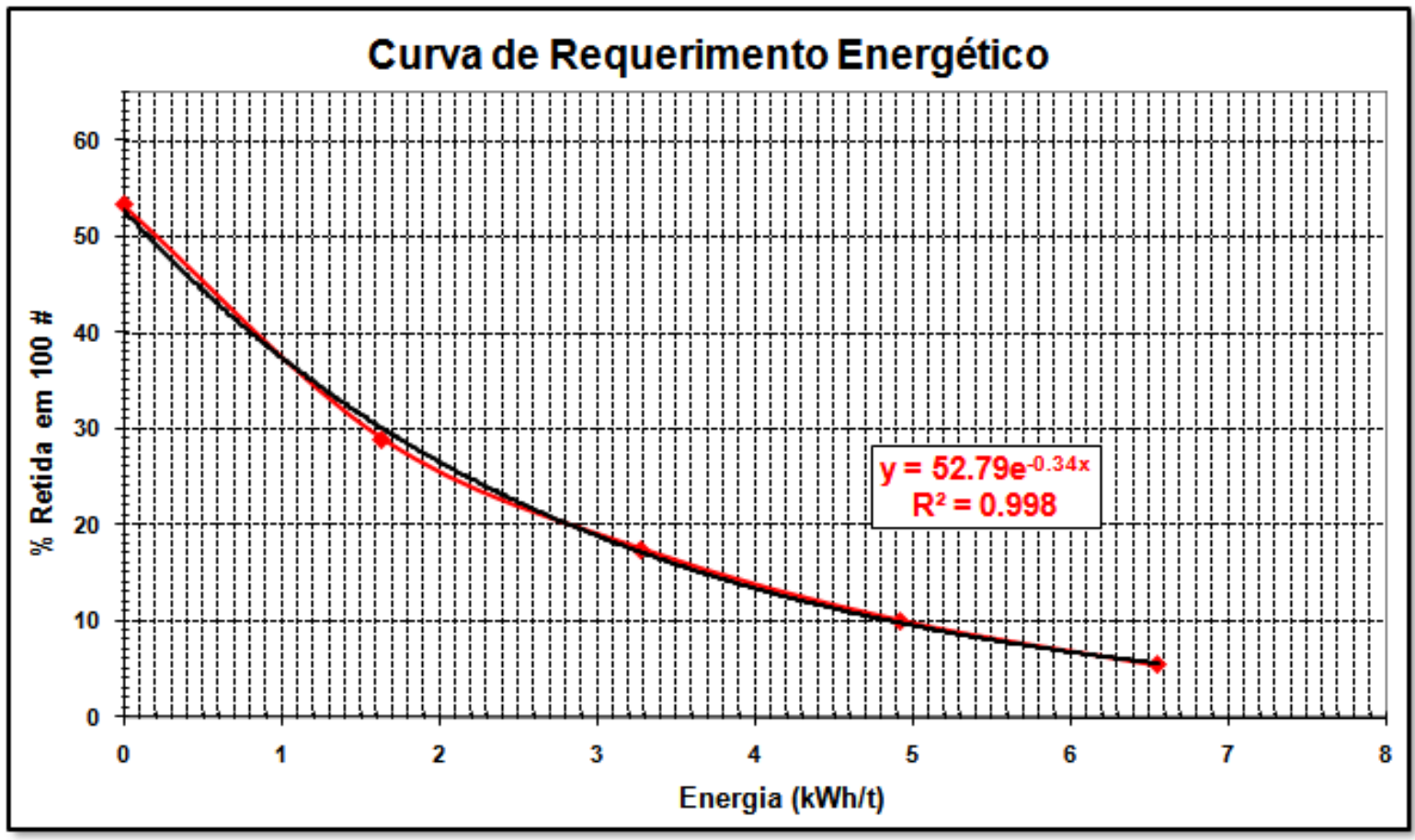

Figura 3.Resultadodo ensaio de requerimento energético com a curva exponencial ajustada. $\mathrm{O}$ valor de energia é calculado considerando $10 \%$ retido em $150 \mu \mathrm{m}$.

Assim, criou-se um banco de dados com cerca de quatrocentas e cinquenta amostras de furos de sonda com resultados de requerimento energético e da determinação de tempo de moagem (DTM), além das análises químicas e mineralógicas. De posse desses dados, o grupo de Geometalurgia da Samarco, uma parceria entre geologia e engenharia de processo, buscou um modelo matemático por regressão linear para cálculo do requerimento energético.

Em paralelo desenvolveu-se um trabalho investigativo inicial com nove amostras coletadas em frentes de lavra, com aproximadamente $400 \mathrm{Kg}$ cada, de diferentes tipos e graus de compacidade. Cada amostra foi submetida a análises granulométrica e química, e aos ensaios de DTM e requerimento energético. $O$ objetivo foi verificar se existiam variáveis que apresentassem correlação com 0 consumo energético da moagem.

Para concepção do modelo de regressão para cálculo do requerimento energético foram utilizadas ferramentas estatísticas no software Minitab para verificar multicolinearidade entre as variáveis selecionadas, análise de best de subset, teste de significância estatística das variáveis no modelo de regressão proposto e análise do ajuste de regressão $r^{2}$ para equação obtida no modelo. Para validação estatística do modelo foi realizado análise de resíduos considerando as suposições de normalidade dos dados, variância constante e independência dos dados.

\footnotetext{
* Contribuição técnica ao $44^{\circ}$ Seminário de Redução de Minério de Ferro e Matérias-primas, 15ํ Simpósio Brasileiro de Minério de Ferro e $2^{\circ}$ Simpósio Brasileiro de Aglomeração de Minério de Ferro, 15 a 18 de setembro de 2014, Belo Horizonte, MG, Brasil.
} 
Para conferência dos resultados reportados pelos modelos de blocos, a energia foi inserida na rotina de reconciliação, considerando os resultados obtidos nos ensaios de requerimento energético realizados nos compostos diários dos concentradores.

\section{RESULTADOS E DISCUSSÃO}

\subsection{Estudo Exploratório - Amostras de Frentes de Lavra}

O trabalho investigativo inicial foi baseado na caracterização de seis amostras de minérios semi compactos, cujos resultados são mostrados na tabela 1.

Tabela 1. Resultados obtidos das análises químicas, análise granulométrica (retido na malha de $3 / 8$ ", $9,53 \mathrm{~mm}$ ) e ensaios de DTM e requerimento energético para as amostras de frentes de lavras.

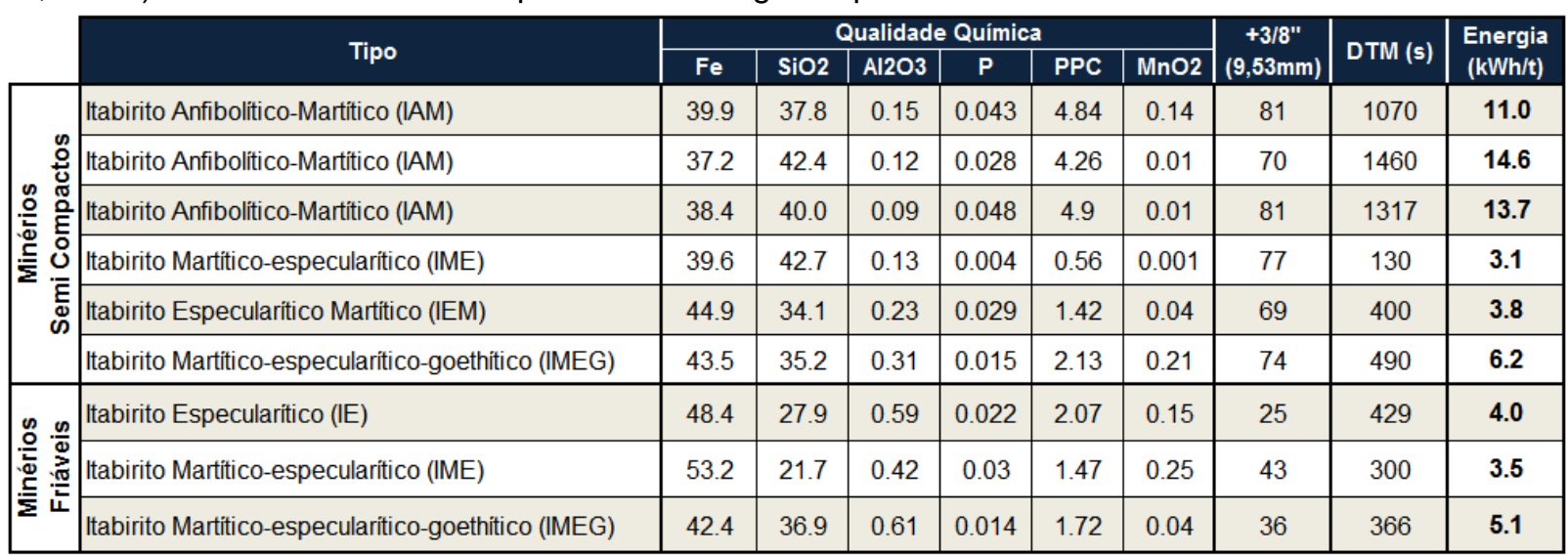

Os valores obtidos de requerimento energético na moagem foram bastante distintos, mesmo apresentando percentual mássico retido na malha de $3 / 8$ " bem próximos. Por exemplo, na amostra 02 do tipo IAM semi compacto o retido em 3/8" foi igual a $70 \%$ e a energia obtida de 14,6kWh/t, por sua vez, na amostra 06 do tipo IEM semi compacto a energia necessária foi de $3,8 \mathrm{kWh} / \mathrm{t}$ mesmo com o retido em $3 / 8$ " igual a $69 \%$.

Considerando a tipologia das amostras, fundamentada na composição mineralógica do minério, é notável que as amostras dos tipos anfibolíticos (amostras 1, 2 e 3) apresentaram valores de energia substancialmente mais elevados do que as amostras dos tipos essencialmente martíticos/especularíticos. Enquanto as amostras dos tipos anfibolíticos apresentaram valores médios de energia de $13,1 \mathrm{kWh} / \mathrm{t}$, as amostras dos tipos com martita e especularita apresentaram valores médio de 4,3kWh/t, independente do percentual retido em 3/8".

Este fato pode ser explicado pela presença significativa da goethita na composição mineralógica dos tipos anfibolíticos, que reflete diretamente no teor de PPC (perda por calcinação). Para os tipos anfibolíticos o teor médio do PPC foi de 4,6\% e para os tipos martíticos/especularíticos o teor de PPC foi em média de 1,56\%. Correlacionando os dados das amostras de PPC com energia, mesmo considerando um número pequeno de amostras, é possível notar no gráfico da figura 4 uma correlação satisfatória entre as variáveis.

\footnotetext{
* Contribuição técnica ao $44^{\circ}$ Seminário de Redução de Minério de Ferro e Matérias-primas, 15ํ Simpósio Brasileiro de Minério de Ferro e $2^{\circ}$ Simpósio Brasileiro de Aglomeração de Minério de Ferro, 15 a 18 de setembro de 2014, Belo Horizonte, MG, Brasil.
} 


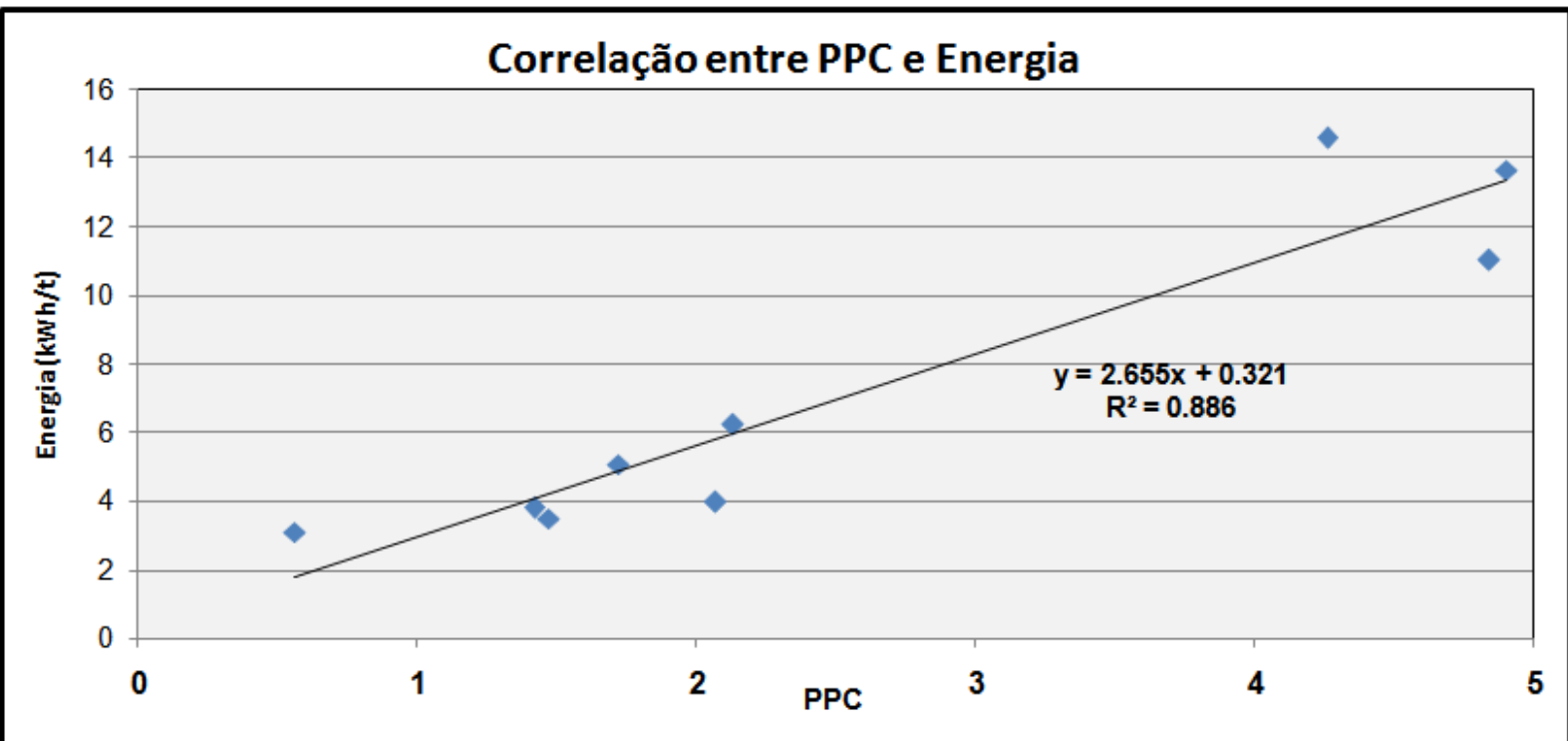

Figura 04. Gráfico de dispersão do teor de PPC com os valores de energia gerando a reta e a equação de regressão linear.

É importante salientar que, novamente, o modelo geológico-tipológico pré-existente, fundamentado na composição mineralógica do minério, se apresenta como imprescindível para um modelo geometalúrgico, gerando entendimento do comportamento do minério nas diversas etapas do beneficiamento.

Comparando os dados de DTM com os de energia, é notável a alta correlação entre estas variáveis (figura 5), levando à conclusão de que este, além da tipologia e do teor de PPC, contribuiriam para a obtenção de um modelo para cálculo do requerimento energético.

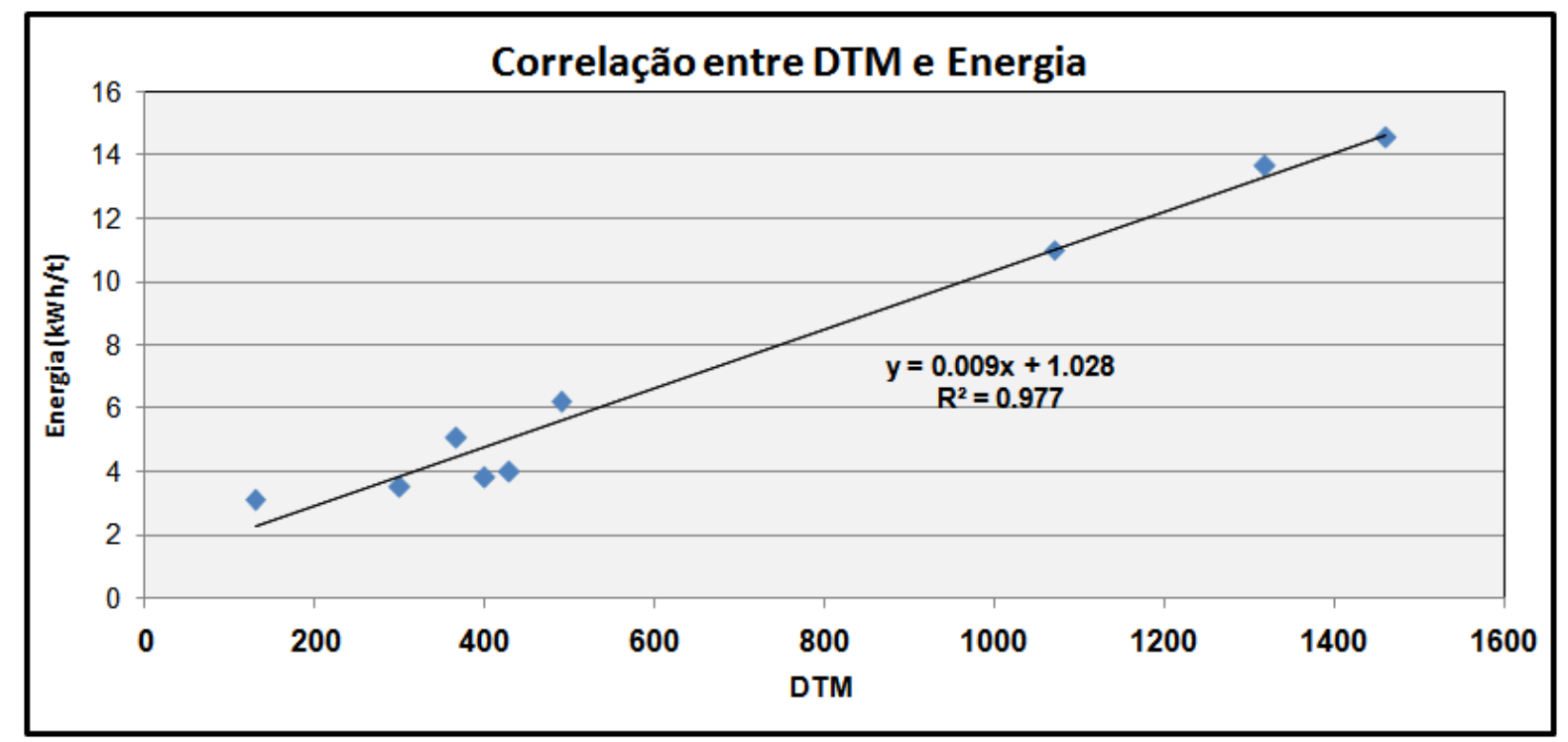

Figura 5. Gráfico de dispersão dos valores de DTM e energia com a reta e equação de regressão linear.

\subsection{Banco de Dados Geológico}

Após a inserção do ensaio de requerimento energético no fluxograma de caracterização das amostras de testemunhos de sonda, foi composto um banco de dados com cerca de quatrocentas e cinquenta amostras. A partir desse conjunto de

* Contribuição técnica ao 44ํ Seminário de Redução de Minério de Ferro e Matérias-primas, 15 Simpósio Brasileiro de Minério de Ferro e 2ํ Simpósio Brasileiro de Aglomeração de Minério de Ferro, 15 a 18 de setembro de 2014, Belo Horizonte, MG, Brasil. 
dados, foi conduzido um trabalho estatístico na busca de um modelo matemático de regressão para o cálculo do requerimento energético a partir das variáveis presentes no banco de dados geológico.

Primeiramente houve um estudo estatístico básico para a seleção das variáveis mais relevantes no resultado do requerimento energético, orientando-se também pelos resultados obtidos do trabalho investigativo inicial, com as amostras de frentes de lavra.

Dentre as variáveis presentes no banco de dados geológico foram previamente selecionadas as seguintes variáveis explicativas:

- DTM (s);

- Teor de Fe no ROM (\%);

- Teor de PPC no ROM (\%);

- Retido acumulado na malha de 3/8" (\%);

- Hematita Especular (HE) da alimentação da flotação (\% volume parcial);

- Hematita Martítica (HM) da alimentação da flotação (\% volume parcial).

O primeiro passo foi verificar se há multicolinearidade entre as variáveis independentes selecionadas para o modelo, ou seja, se as variáveis explicativas selecionadas são correlacionáveis entre elas. A multicolinearidade pode causar sérios efeitos na estimativa dos coeficientes de regressão e na aplicabilidade geral do modelo estimado. Desta forma, foi feita uma matriz de correlação para tal verificação, conforme demonstrado na figura 6 .

\begin{tabular}{|c|c|c|c|c|c|}
\hline \multicolumn{2}{|c|}{$\mathbf{D T M}$} & $\mathbf{F e}$ & $\mathbf{P P C}$ & $\mathbf{3 / 8}$ & HE \\
\cline { 2 - 6 } \multicolumn{1}{|c|}{$\mathbf{F e}$} & $-0,238$ & & & & \\
& 0,000 & & & & \\
\hline PPC & 0,294 & 0,397 & & & \\
& 0,000 & 0,000 & & & \\
\hline $\mathbf{3 / 8 "}$ & 0,533 & $-0,129$ & 0,236 & & \\
& 0,000 & 0,013 & 0,000 & & \\
\hline HE & $-0,185$ & 0,061 & $-0,417$ & $-0,049$ & \\
& 0,000 & 0,240 & 0,000 & 0,349 & \\
\hline HM & $-0,198$ & $-0,173$ & $-0,644$ & $-0,368$ & $-0,010$ \\
& 0,000 & 0,001 & 0,000 & 0,000 & 0,853 \\
\hline
\end{tabular}

Figura 6. Matriz de correlação entre as variáveis independentes selecionadas para o modelo de regressão.

Pelos valores gerados, $<0,90$, é possível afirmar que não há multicolinearidade entre as variáveis.

Para definição do melhor modelo de regressão que explique o resultado de requerimento energético, foi realizada uma análise do Best de Subset com todas as seis variáveis explicativas, conforme os critérios de $\mathrm{R}^{2}$ ajustado (quanto maior melhor), Mallows $C P$ (valor próximo ao número de variáveis +1 ) e variância média "S" (quanto menor melhor). (Figura 7).

\footnotetext{
* Contribuição técnica ao 44 Seminário de Redução de Minério de Ferro e Matérias-primas, 15오 Simpósio Brasileiro de Minério de Ferro e 2ํ Simpósio Brasileiro de Aglomeração de Minério de Ferro, 15 a 18 de setembro de 2014, Belo Horizonte, MG, Brasil. 


\begin{tabular}{|c|c|c|c|c|c|c|c|c|c|c|}
\hline Vars & R-Sq & R-Sq (adj) & Mallows CP & $\mathbf{S}$ & DTM & $\mathrm{Fe}$ & PPC & $3 / 8 "$ & HE & $\mathrm{HM}$ \\
\hline 1 & 60.4 & 60.3 & 547.0 & 2.5077 & $\mathrm{x}$ & & & & & \\
\hline 1 & 45.9 & 45.7 & 884.3 & 2.9327 & & & & $x$ & & \\
\hline 2 & 74.1 & 73.9 & 233.0 & 2.0328 & $x$ & & $x$ & & & \\
\hline 2 & 72.5 & 72.4 & 269.1 & 2.0930 & $\mathrm{x}$ & & & & & $\mathbf{x}$ \\
\hline 3 & 81.7 & 81.5 & 58.6 & 1.7110 & $\mathrm{x}$ & & $\mathbf{x}$ & $\mathbf{x}$ & & \\
\hline 3 & 77.0 & 76.8 & 167.4 & 1.9176 & $x$ & & & $x$ & & $\mathrm{x}$ \\
\hline 4 & 83.3 & 83.1 & 23.5 & 1.6367 & $\mathrm{x}$ & $\mathrm{x}$ & $\mathbf{x}$ & $\mathbf{x}$ & & \\
\hline 4 & 82.4 & 82.2 & 44.4 & 1.6803 & $\mathrm{x}$ & & $\mathbf{x}$ & $\mathbf{x}$ & $\mathbf{x}$ & \\
\hline 5 & 83.5 & 83.3 & 19.5 & 1.6262 & $x$ & $\mathbf{x}$ & $\mathrm{x}$ & $\mathbf{x}$ & $x$ & \\
\hline 5 & 83.5 & 83.3 & 20.0 & 1.6273 & $x$ & $x$ & $x$ & $x$ & & $\mathrm{x}$ \\
\hline 6 & 84.2 & 83.9 & 7.0 & 1.5972 & $x$ & $x$ & $x$ & $x$ & $x$ & $x$ \\
\hline
\end{tabular}

Figura 7. Análise do Best de Subset com destaque para o modelo de regressão escolhido.

O resultado apresentado na análise de Best de Subset sugere a escolha do modelo de regressão considerando todas as seis variáveis como melhor opção. Neste modelo ajustado, $83,9 \%$ da variação do requerimento energético ( $R^{2}$ ajustado) é explicado por essas variáveis significativas. O Mallows CP igual a 7 e o valor de "S" mais baixo confirmam a escolha.

Desta forma, foi determinada a equação de regressão para o requerimento energético. Na figura 08 é apresentado o resultado da análise de regressão dado pelo Minitab.

\begin{tabular}{|c|c|c|c|c|}
\hline \multirow{2}{*}{\begin{tabular}{|c|}
$\begin{array}{c}\text { Requerimento } \\
\text { Energético } \\
\text { (kWh/t) }\end{array}$ \\
Predictor
\end{tabular}} & \multicolumn{4}{|c|}{$=3.51+0.221^{\star} \mathrm{DTM}-0.0538^{\star} \mathrm{Fe}+0.517^{\star} \mathrm{PPC}+0.0401^{\star} 3 / 8^{\prime \prime}-0.0281^{\star} \mathrm{HE}-0.0211^{\star} \mathrm{HM}$} \\
\hline & coef & SE coef & $\mathrm{T}$ & $\mathrm{P}$ \\
\hline Constant & 3.5131 & 0.6100 & 5.76 & 0.000 \\
\hline DTM & 0.22137 & 0.01300 & 17.03 & 0.000 \\
\hline $\mathrm{Fe}$ & -0.05376 & 0.01312 & -4.10 & 0.000 \\
\hline PPC & 0.51671 & 0.06962 & 7.42 & 0.000 \\
\hline $3 / 8^{\prime \prime}$ & 0.040092 & 0.003536 & 11.34 & 0.000 \\
\hline $\mathrm{HE}$ & -0.028110 & 0.007258 & -3.87 & 0.000 \\
\hline $\mathrm{HM}$ & -0.021111 & 0.005543 & -3.81 & 0.000 \\
\hline$S=1.59718$ & & $\mathrm{R}-\mathrm{Sq}=84.2 \%$ & & R-Sq $(\operatorname{adj})=83.9 \%$ \\
\hline
\end{tabular}

Figura 8. Equação gerada na análise de regressão.

No modelo ajustado $83,9 \%$ da variabilidade total do requerimento energético é explicado pelas seis variáveis significativas. A equação de regressão (1) apresentou teste de significância satisfatório com $P$-value $=0$.

Para validação estatística do modelo ajustado foi realizado análise de resíduos considerando as suposições de normalidade dos dados, variância constante e independência dos dados, apresentada na figura 9.

\footnotetext{
* Contribuição técnica ao $44^{\circ}$ Seminário de Redução de Minério de Ferro e Matérias-primas, $15^{\circ}$ Simpósio Brasileiro de Minério de Ferro e 2ํ Simpósio Brasileiro de Aglomeração de Minério de Ferro, 15 a 18 de setembro de 2014, Belo Horizonte, MG, Brasil. 


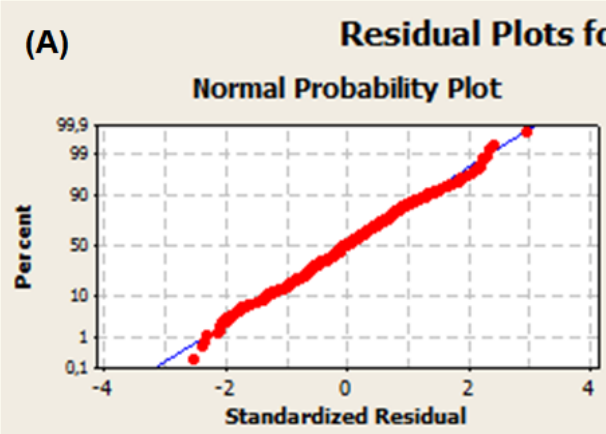

\section{Energia (kWh/t)}

(C)

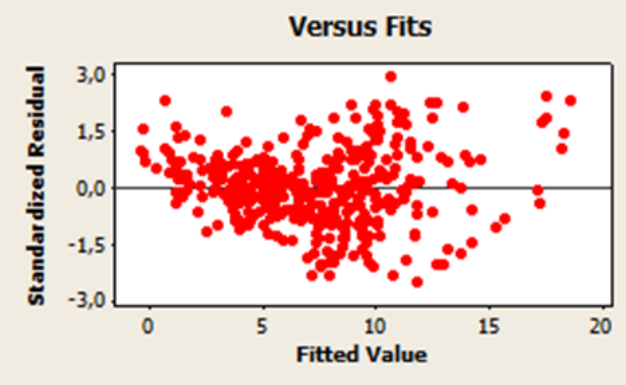

(B) Histogram

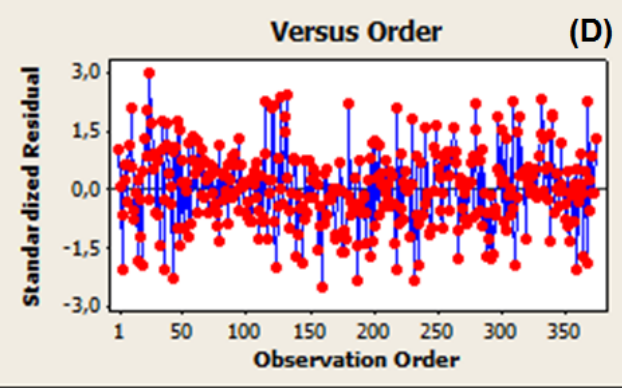

Figura 9. Imagem do Minitab da análise de resíduos pelas suposições de normalidade dos dados, imagem (A) e (B), variância constante, imagem (C), e independência dos dados, imagem (D).

Pelas imagens da figura 9 é possível concluir que todas as suposições da análise de resíduos foram atendidas satisfatoriamente. A suposição de normalidade é atendida, pois os pontos da imagem (A) estão sobre a reta e o histograma da imagem (B) exibe um padrão normal. A suposição de variância constante é atendida, pois os pontos da imagem (C) exibem padrão aleatório. Por último, a suposição de independência dos dados é atendida, pois os pontos da imagem (D) estão espalhados em torno do valor zero, não existindo nenhum valor pela ordem de coleta dos dados.

Depois de definido o modelo matemático, o requerimento energético de moagem foi calculado nos modelos de blocos de longo e curto prazo, a partir das variáveis estimadas. Desta forma, seja no sequenciamento de lavra da reserva ou nos planos de lavra de curto prazo, é reportado o valor de requerimento energético, oferecendo uma resposta direta do comportamento do minério na etapa de moagem. Assim é possível antever a necessidade de investimentos nas etapas de moagem para as usinas existentes e auxiliar no dimensionamento de novas instalações. Para o curto prazo, torna-se necessário adequar o blending de minério respeitando a energia instalada nos concentradores da Samarco. Na figura 10, é apresentado o mapa da mina de Alegria Norte conforme valores de requerimento energético do modelo de blocos de curto prazo.

\footnotetext{
* Contribuição técnica ao $44^{\circ}$ Seminário de Redução de Minério de Ferro e Matérias-primas, 15오 Simpósio Brasileiro de Minério de Ferro e 2ํ Simpósio Brasileiro de Aglomeração de Minério de Ferro, 15 a 18 de setembro de 2014, Belo Horizonte, MG, Brasil.
} 

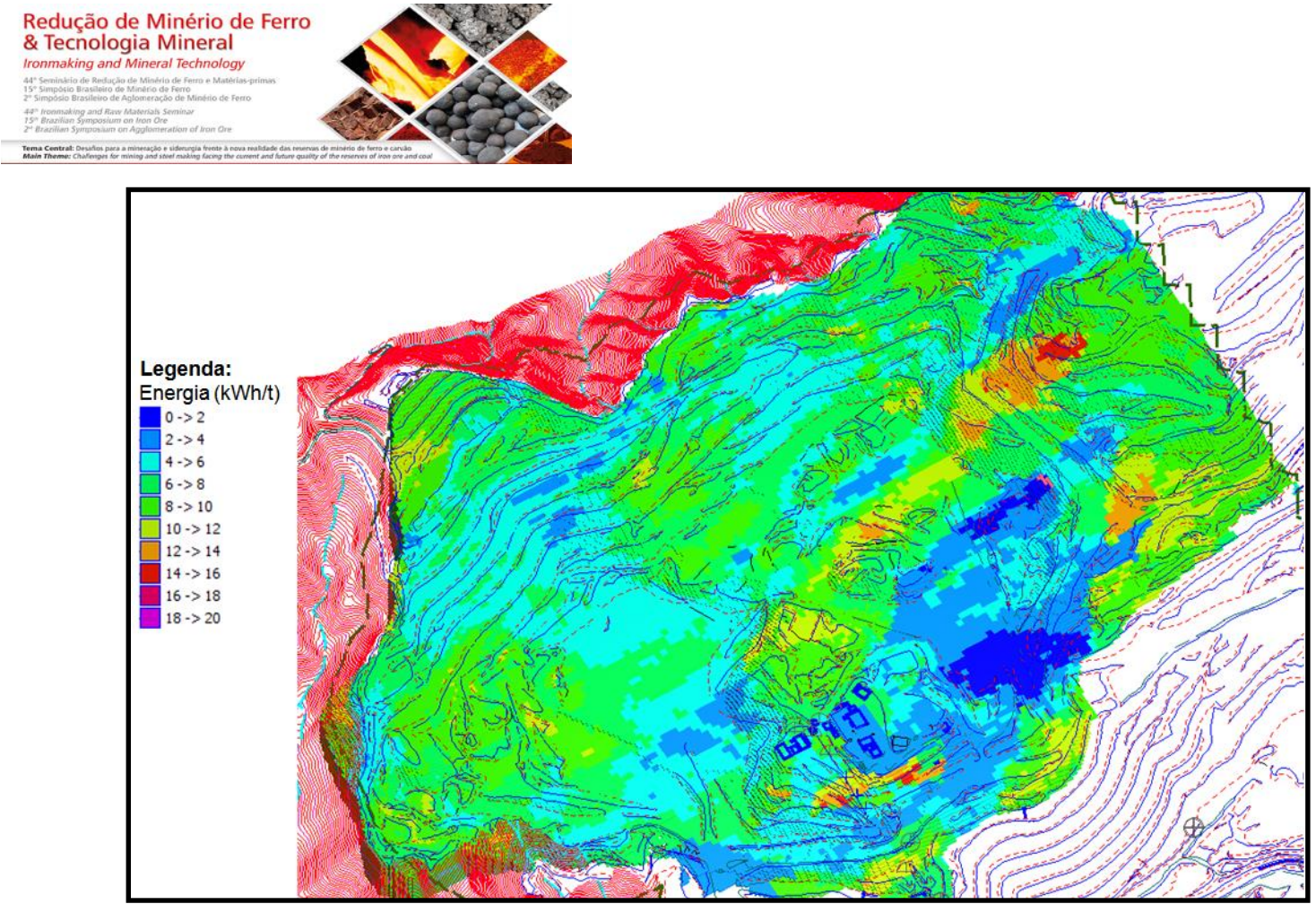

Figura 10. Mapa da mina de Alegria Norte com distribuição dos valores de energia em kWh/t.

Em 2014, o requerimento energético foi inserido na rotina de reconciliação entre os dados estimados dos modelos de blocos de curto e longo prazo com os dados reais, obtidos nas análises das amostras dos concentradores. Os dados reais do requerimento energético são provenientes dos compostos mensais dos concentradores submetidos aos ensaios de bancada. No gráfico da figura 11, está apresentada a reconciliação do modelo de blocos de curto prazo para os meses de janeiro a abril de 2014. É possível observar que a aderência entre os valores estimados com os valores reais são satisfatórios.

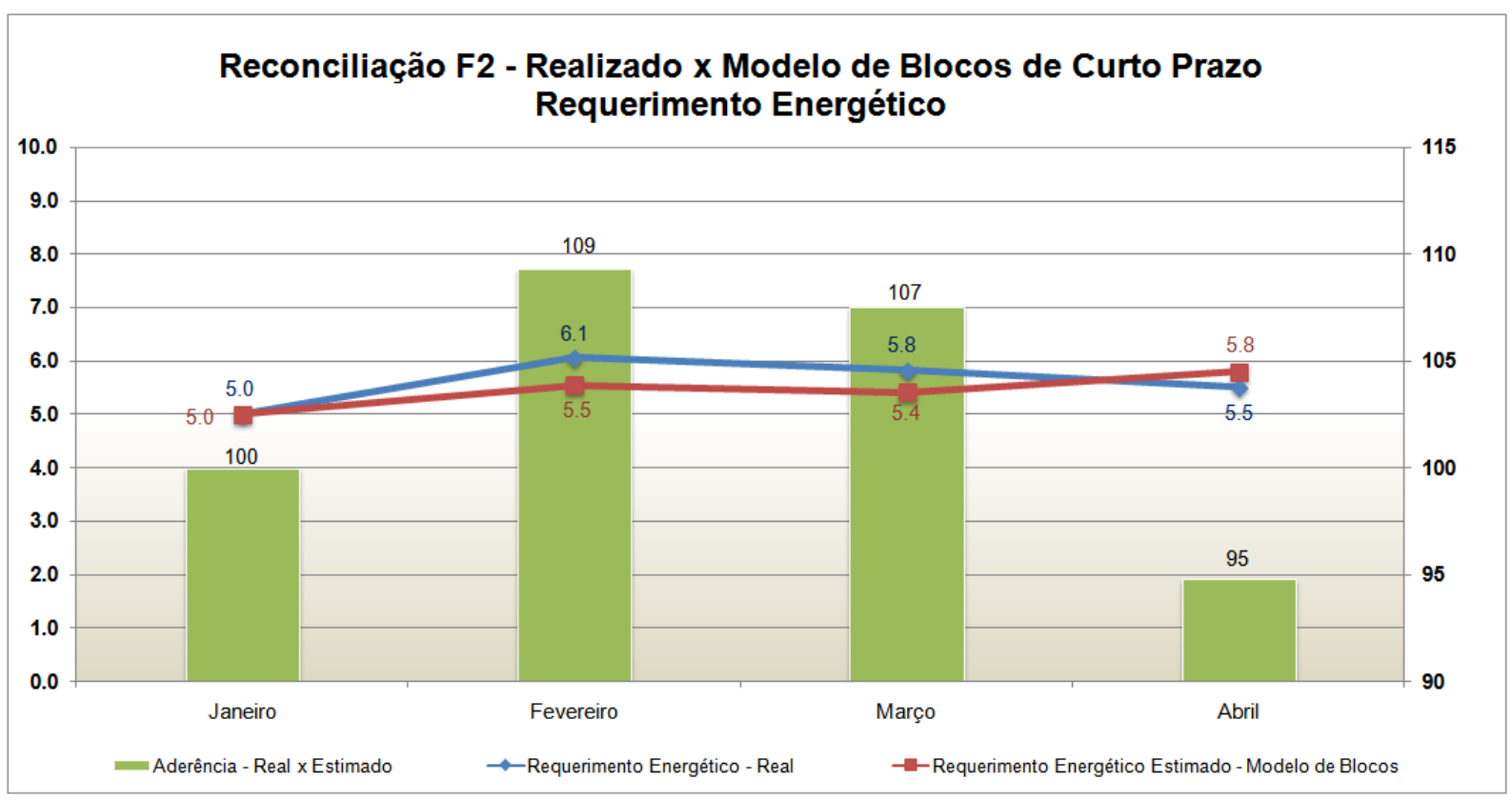

Figura 11. Gráfico da reconciliação do requerimento energético para o modelo de blocos de curto prazo.

\footnotetext{
* Contribuição técnica ao $44^{\circ}$ Seminário de Redução de Minério de Ferro e Matérias-primas, $15^{\circ}$ Simpósio Brasileiro de Minério de Ferro e $2^{\circ}$ Simpósio Brasileiro de Aglomeração de Minério de Ferro, 15 a 18 de setembro de 2014, Belo Horizonte, MG, Brasil.
} 


\section{CONCLUSÃO}

O requerimento energético é a variável que melhor reflete o comportamento dos tipos de minério na etapa de moagem, fornecendo a previsão do consumo específico de energia para os moinhos industriais.

A caracterização tipológica baseada na composição mineralógica, a classificação do minério quanto à compacidade baseada no retido acumulado na fração $3 / 8$ " e a composição química, fornecem importante embasamento no entendimento do requerimento energético na etapa de moagem e possibilitaram a construção de um modelo matemático.

A inserção do requerimento energético ( $\mathrm{kWh} / \mathrm{t})$ nos modelos de blocos disponibilizou importante ferramenta ao planejamento de lavra de curto prazo para a adequação do minério à energia de moagem instalada e ao planejamento de longo prazo fornecer subsídios à Engenharia de Processo para antever a necessidade de revamp nas usinas existentes e/ou auxiliar no dimensionamento de novas instalações de moagem.

\section{Agradecimentos}

Agradecemos à Samarco pela oportunidade de desenvolvimento, ao João Pedro, Ivan, Wagner Milagres e Marcos Gomes pelo apoio e incentivo ao grupo de geometalurgia e à equipe do LCP pela colaboração e auxílio nos testes realizados.

\section{REFERÊNCIAS}

1 Dorr JVN. Physiographic, Stratigraphic and Structural Development of the Quadrilátero Ferrífero, Minas Gerais, Brazil. Washington, Geological Survey Professional Paper 641A, $110 \mathrm{p}, 1969$.

2 Hasui Y. et al., Mina de Alegria (Porção Ocidental). Parte I - Tipologia dos Constituintes da Jazida de Ferro. Geociências, São Paulo, 1994; 13(1): 101-119.

3 Dorr JVN. Supergene Iron of Minas Gerais, Brazil. Economic Geology, 1964; 59: 12031240.

4 Costa AGD, Rocha JMP, Bonfioli LE, Vieira CB. A importância do modelamento geológico-tipológico no controle de qualidade dos concentrados e pelotas e minério de ferro da Samarco Mineração S/A. in: XXIX Seminário de Redução de Minério de Ferro, 1998, Belo Horizonte-MG. p. 545-555.

5 Costa AGDC, Costa FJO, Bonfioli LE, Rodrigues ML. Geologia de mina na Samarco Mineração: um suporte ao planejamento de curto prazo/controle de qualidade, com ênfase no controle mineralógico e na previsibilidade do comportamento dos tipos de minério no processo. In: III Simpósio Brasileiro de Minério de Ferro, 2001, Ouro PretoMG. 10p.

6 Donda JD. Um método para prever o consumo específico de energia na (re)moagem de concentrados de minérios de ferro em moinhos de bolas. Tese Doutorado. Belo Horizonte-MG: Universidade Federal de Minas Gerais; 2003.

7 Donda JD, Galinari CM, Rabelo PJB. O controle da eficiência energética nos circuitos de pré-moagem e moagem primária da Samarco Mineração. Simpósio Brasileiro de Minério de Ferro - ABM, São Paulo-SP, p. 144-150, 1999.

* Contribuição técnica ao 44 Seminário de Redução de Minério de Ferro e Matérias-primas, $15^{\circ}$ Simpósio Brasileiro de Minério de Ferro e $2^{\circ}$ Simpósio Brasileiro de Aglomeração de Minério de 